\title{
AN INVESTIGATION OF INFORMATION TECHNOLOGY-ENABLED REMOTE MANAGEMENT AND REMOTE WORK ISSUES
}

\author{
D. Sandy Staples \\ Department of Information Systems \\ The University of Melbourne \\ Parkville, Victoria 3052 Australia \\ Phone: +61393449260 \\ E-mail: s.staples@dis.unimelb.edu.au
}

\begin{abstract}
A two phase research study was done to investigate remote work and remote management issues. In Phase 1 , focus groups were carried out with remote managers and remote employees to identify key issues. The most common key issues dealt with communications, information technology, leadership and coaching, teamwork, building trust, and performance management. In the second phase, a questionnaire was used to test hypotheses developed from phase 1. The findings supported that higher trust leads to higher job satisfaction and lower job stress, and that more communication between the manager and the remote employee develops higher levels of employee organizational commitment.
\end{abstract}

\section{INTRODUCTION}

Terms such as downsizing, restructuring, delayering, telecommuting, and virtual organizations are common in today's business literature. All these phenomena have at least one thing potentially in common. They can move the manager farther from the worker, and vice versa. This can occur because the span of control is larger (i.e., have more people to manage) or simply because the organization is structured to be a virtual one, where few people are physically located near each other. Therefore, it is becoming common for managers to have to manage some or all of their employees remotely. The purpose of this research study was to investigate the practice of managing people remotely and the potential enabling role of information technology in creating the ability to work remotely.

The concept of remote management is defined as managing employees who work in a physically separate location from their managers. The employee's location can vary considerably from working at another company office or in their home, to working at a customer's location or out of their car. Employees working at home are by definition telecommuting; however, telecommuting is just one work arrangement that results in remote management. As suggested by Jenner (1994), telecommuting is only a small part of the virtual workplace, in which people work together while being physically distant from each other.

The concept of virtual organizations and the resulting remote management is not new. For example, sales organizations have been working remotely for decades or more. Handy (1995) stated that what is new is the technology that allows the concept to be applied much more broadly than in the past. The basic assumptions of modern organization theory and practice, such as the need to physically group people and units together to provide for coordination and supervision, are being increasingly invalidated by information technology (IT). Coordination of tasks, functions and people no longer require physical proximity (Lucas and Baroudi, 1994; Snell, 1994).

Information technology plays a key enabling role for the new forms of organization (Handy, 1995; Lucas \& Baroudi, 1994; Freedman, 1993; Greengard, 1994; O'Hara-Devereaux \& Johansen, 1994). The technology allows tasks to be distributed in different places and executed at different times while integrating and effectively controlling the whole process (Mowshowitz, 1994). The virtual workplace provides access to information needed to do a job anywhere, anytime, anyplace and the latest in communication technology is used to accomplish this (Jenner, 1994). Bleecker (1994) predicts that integrated computer and communication technology will transform corporations into collaborative networks linking people together.

Remote management and remote work also appears to be a growing phenomena and there is a high level of interest in the topic at the practitioner level. Illingworth (1994) reports that companies are asking about the impact the virtual office concept is having on worker satisfaction, individual identity, and corporate community. Experience with this study supports Illingworth's claim since support for this study has been strong from industry.

The research program was broken into two phases. Exploratory research was first undertaken to investigate the suggestions in the literature and develop hypotheses for testing, via a questionnaire, in phase 2. Therefore, this paper is organized as follows. Section 2 reviews literature relevant to remote management. Section 3 presents the methodology and results of phase 1 of the study. Section 4 presents the hypotheses to be tested in phase 2 . Section 5 discusses the methodology used for the second phase 
of the study and reviews the findings. The last section comments on the findings, their contributions and limitations.

\section{CURRENT STATE OF THE LITERATURE}

Although the literature that addresses remote management is sparse and based on anecdotal evidence, it does contain some suggestions for managing people that are physically separate. Developing trust and minimal supervision expectations are important since it is very difficult to supervise and control remote employees (Handy, 1995; Lucas \& Baroudi, 1994; Snell, 1994). However, trusting employees often goes against a managerial tradition that believes control and efficiency are closely linked and that you can't have one without the other (Handy, 1995). Gerber (1995) suggests that trust can be generated in two ways. It comes from developing a relationship through communications and informal activities, as well as from performance (i.e., deliver on promises and be competent).

Another remote management issue from the literature is the ability of remote managers to manage the subtle processes of cultural and political change in organizations (Walsham, 1994). Morgan (1988) suggests that the values and beliefs (i.e., corporate culture) of an organization serves as a guide to help parts of the organization move in the same direction in a highly decentralized style of management. Maintaining the corporate culture in a remote environment (Illingworth, 1994; Greengard, 1994) and changing the culture to accommodate the new way of working that IT enables (Lucas \& Baroudi, 1994; Beyers, 1995; Bleecker, 1994; Morgan, 1988) are challenges that remote managers and workers face. Illingworth (1994) and others (e.g., Gerber, 1995; Mowshowitz, 1994; Greengard, 1994) also suggest that remote managers need to move towards result-oriented assessments (i.e., a focus on what did you contribute today, not whether or not you were at your desk), rather than process-orientated assessments. Mowshowitz (1994) suggests that "the essence of virtual organization is the management of goaloriented activity in a way that is independent of the means for its realization" (p. 270).

The telecommuting literature also indicates that the management of people who are remote from their managers (i.e., in this case, working at home) is a major issue. Managers are concerned that telecommuting will hamper their ability to manage effectively. The fear of lost managerial control is reported to be a significant factor preventing widespread adoption of telecommuting (e.g., DeSanctis, 1984; Duxbury, Higgins \& Irving, 1987; Roderick \& Jelley, 1991; Phelps, 1985; Savage, 1988; \& Nilles, 1985). Managers fear that they will have to change their management style since they cannot rely on visual contact for monitoring and control. Several researchers suggest that a more result-oriented management style is needed (Olson, 1988; Judkins et al., 1985; Hamilton, 1987; Metzger \& Von Glinow, 1988; Duxbury et al., 1987). Trust is also suggested as being a key ingredient to manage telecommuters as well as a shift in management from being a passer of information to being a leader or coach (Duxbury et al., 1987; Savage, 1988;).

Beyers (1995) suggests that virtual organizations need virtual management which implies fewer boundaries, more interaction supported electronically, and increasingly direct communication from one to another without the traditional organizational structures (i.e., moving through a structure to do what must be done). Managers' roles will change as traditional, hierarchical methods are no longer appropriate (Snell, 1994; Jenner, 1994). Lucas \& Baroudi (1994) suggest that this creates misgivings about supervision in the typical manager.

In short, the literature suggests that operating in a remote environment will bring different management challenges and perhaps require a different management style. Operating on a basis of trust between the manager and employee will become more important, as will the need for focusing more on the results achieved rather than the process used. Managers will also face challenges managing the corporate culture and corporate politics which results from remote working arrangements.

\section{PHASE 1 - EXPLORATORY RESEARCH}

\section{Research Methodology}

Focus group interviews were chosen as the method to gather data. Focus groups were conducted with both remote managers and remote employees. In order to obtain homogeneous participants (Krueger, 1989), where possible, separate focus groups were conducted with manager participants and manager employees. Focus groups were conducted in three modes due to logistical needs: face-to-face, teleconference, and combined (some people were face-to-face while others phoned into the meeting room). Conducting focus groups via teleconference made it possible to reach participants over a much larger geographic area than would have been possible if only face-to-face focus groups were used.

Five organizations participated in this study, three of which were private sector firms (i.e., Hewlett Packard (HP), Northern Telecom (NT), Imperial Oil (Imperial)), and two of which were public sector organizations (i.e., ministries of provincial governments in Canada). These five organizations had a 
large variance in the information technology (i.e., ranging from the telephone to groupware and videoconferencing) used to manage remotely and work remotely which was advantageous for the study. Managers were selected who had employees who reported directly to them and who worked from a different location than the employee. Employees were selected who worked in a different location than their manager. Almost all of the employees worked in different cities than the city where their manager had his/her office. In addition, when it was possible, remote managers and remote employees who had a reputation for either managing or working effectively in a remote environment were specifically targeted. This was done since data were being collected on best practices.

Table 1 summarizes the number and type of participants. A total of 104 people participated in nineteen focus groups, split fairly evenly between remote managers (58 participants; $56 \%$ ) and remote employees (46 participants; $44 \%$ ). Sixty percent $(n=63)$ of the participants worked in Canada, thirtyseven percent $(n=38)$ worked in the United States, and three percent $(n=3)$ of the participants worked in England. The managers and employees were not paired. The participants carried out a wide range of job functions.

Table 2: Summary of Focus Group Participation

\begin{tabular}{|l|c|c|c|c|c|c|c|}
\hline & \multicolumn{3}{|c|}{ Focus Group Participants } & \multicolumn{3}{c|}{ Number and Type of Focus Group } \\
\hline Organization & Managers & Employees & Total & $\begin{array}{c}\text { Face-to- } \\
\text { Face }\end{array}$ & $\begin{array}{c}\text { Telecon- } \\
\text { ference }\end{array}$ & Combined & Total \\
\hline HP & 19 & 17 & 36 & 3 & 5 & 0 & 8 \\
\hline NT & 10 & 11 & 21 & 0 & 4 & 0 & 4 \\
\hline Imperial & 5 & 9 & 14 & 0 & 1 & 2 & 3 \\
\hline Ministry 1 & 13 & 9 & 22 & 2 & 1 & 0 & 3 \\
\hline Ministry 2 & 11 & 0 & 11 & 1 & 0 & 0 & 1 \\
\hline Totals & 58 & 46 & 104 & 6 & 11 & 2 & 19 \\
\hline
\end{tabular}

\section{Phase 1 Findings - Key Issues Regarding Working Remotely and Managing Remotely}

Each participant in the focus groups identified the top three issues from their perspective and ranked them in descending order. The key issues were examined to eliminate any duplication and then grouped into categories. This analysis identified 13 relatively distinct categories of issues which are presented in Table 2. Many of the issues within the various categories are interrelated and Table 2 does not indicate any ranking of the issue by the focus group participants, just that it was identified as a key one.

The category that had the most key issues identified in it was the communications category. Fourteen of the nineteen focus groups identified some communication aspect as a key remote management issue. Typical communication issues included: keeping remote sites in the communication loop and having an equal information transfer for remote and non-remote sites; how can you be confident that you will get the required information about critical issues; the communication skills required; the loss/lack of informal contact; how to replace the non-verbal signals lost by less face-to-face communications; how to get timely access, both for managers to employees and vice versa, and timely response to messages; communications between manager and employees and between peers and management for sharing ideas and keeping in touch; how to deliver negative feedback remotely; and, communications to ensure that the roles of everyone in a work group/team are clear.

The second most frequently mentioned category of key remote management issues (68\% of the focus groups) pertained to information technology (IT) equipment, support and training. IT was clearly found to be a key enabler of effective remote management and many focus groups had suggestions for improvements in their organizations. Participants from the organizations that were less technologically advanced in their IT infrastructure were more likely to identify IT key issues than were those from the IT advanced organizations (i.e., NT and HP). Information technology issues identified by focus groups included: the lack of information technology equipment and support; that more effective information technology was needed to support communication efforts; and, the need for an infrastructure to support technical and logistical support needs.

Teamwork issues and leadership/coaching issues were the next most frequently mentioned key issues. This highlights the difficulty of working with and communicating with people who are located in different locations. Some of the issues identified dealt with: how to coach and lead remotely; how to develop employees remotely; and, how to building relationships remotely and a feeling of being part of a remote team. 
Table 3: Summary of Key Remote Management Issues in the Five Organizations

\begin{tabular}{|l|c|c|c|c|c|c|}
\cline { 2 - 7 } \multicolumn{1}{c|}{} & \multicolumn{3}{c|}{ Number of focus groups that identified key issues in the } & \multicolumn{1}{c|}{ category* } \\
\hline Issue Categories & HP & NT & Imperial & Ministry 1 & Ministry 2 & $\begin{array}{c}\text { Overall } \\
\%\end{array}$ \\
\hline Communications & $50 \%$ & $75 \%$ & $100 \%$ & $100 \%$ & $100 \%$ & $74 \%$ \\
\hline Information Technology & $63 \%$ & $50 \%$ & $100 \%$ & $67 \%$ & $100 \%$ & $68 \%$ \\
\hline Leadership/Coaching & $75 \%$ & $100 \%$ & $33 \%$ & $33 \%$ & 0 & $63 \%$ \\
\hline Teamwork & $38 \%$ & $100 \%$ & $67 \%$ & $67 \%$ & $100 \%$ & $63 \%$ \\
\hline $\begin{array}{l}\text { Performance } \\
\text { Management }\end{array}$ & $63 \%$ & $75 \%$ & $33 \%$ & $67 \%$ & $100 \%$ & $63 \%$ \\
\hline $\begin{array}{l}\text { Travel Time/Family } \\
\text { Balance }\end{array}$ & $63 \%$ & $100 \%$ & $33 \%$ & $33 \%$ & 0 & $58 \%$ \\
\hline Differences across sites & $38 \%$ & $75 \%$ & $33 \%$ & 0 & $100 \%$ & $42 \%$ \\
\hline Isolation & $13 \%$ & $50 \%$ & $67 \%$ & $33 \%$ & 0 & $32 \%$ \\
\hline $\begin{array}{l}\text { Career Development/ } \\
\text { Recognition }\end{array}$ & $25 \%$ & 0 & $33 \%$ & $33 \%$ & 0 & $21 \%$ \\
\hline New Employees & $38 \%$ & $25 \%$ & 0 & 0 & 0 & $21 \%$ \\
\hline $\begin{array}{l}\text { Remote environment } \\
\text { brings different mg't } \\
\text { challenges }\end{array}$ & 0 & 0 & 0 & $100 \%$ & 0 & $16 \%$ \\
\hline Administrative Support & $25 \%$ & 0 & $33 \%$ & 0 & 0 & $16 \%$ \\
\hline Training & 0 & 0 & $67 \%$ & $33 \%$ & 0 & $16 \%$ \\
\hline
\end{tabular}

* The numbers in table 2 show the percentage of times the issue was identified as being a key one in a focus group conducted in that organization. For example, in 50\% (i.e., 4 out of 8 ) of the HP focus groups, someone identified a communication issue as being one of their top three issues (i.e., a key issue).

Over half the focus groups mentioned issues of performance management, including how to build trust and a relationship between managers and employees. Performance management was largely a management issue as it was mentioned in most management participant focus groups. Some of the key issues identified by the focus group participants were: how to gather information remotely to carry out employee appraisals, especially softer information; how to build trust between managers and employees; accountability issues including how to measure productivity; how to identify employees who are struggling and help them; and, that managers have to change their expectations regarding accountability. Trust is needed that the job is being done.

About half the focus groups also mentioned travel time/family balance issues. The distances between manager and employees were very large for many of the participants (e.g., one manager had several employees across the country - Canada or the US), which created large travel times for face-to-face meetings between the manager and employee or for the work group/team. The time burden this travel imposes on a schedulc can be sevcre. Also, for work-at-home employees, balancing family and work life can be an issue since it can be difficult to separate the work environment.

Slightly under half of the focus groups identified key issues caused by differences among sites. These ranged from problems caused by working across different countries or regions which had different languages, cultures and laws, to different standards being adopted at different sites, to the perception that different organizational cultures likely develop at different sites. A key concern in this category among HP employees was how to maintain their strong corporate culture so that it was consistent across the organization.

Issues dealing with employee career development and lack of recognition, hiring and training new employees for remote postings, recognizing that remote management is different and it brings different management challenges, training, and administrative support were all identified by a few focus groups as key remote management issues. Lack of administrative support was a key issue for work-at-home employees.

Table 2 presented the key issues for both the managers and employees combined. Further analysis was done to determine if there were differences between manager's and employees' key issues. A number of differences were found. Managers were more likely to identify key issues dealing with 
leadership/coaching, performance management, and new employees. This is not surprising given that the issues are associated with tasks that would normally be thought of as management responsibilities. However, employees were not oblivious to these issues. Half of the employee focus groups identified key issues dealing with leadership/coaching, and performance management.

Employees were much more likely to identify key issues dealing with information technology, travel time/family balance, isolation, and administrative support. This is not surprising given that these issues more strongly effect the employee than the manager. In most cases, it is the employee that is isolated from others in the organization and who suffers from the lack of administrative support. The employee depends heavily on IT and feels the lack of support for it more severely than a manager who has a corporate office, although $45 \%$ of the manager focus groups identified IT issues. While both managers and employees brought up travel time/family balance issues, employees did so more often. This likely reflects that either the employee is doing the majority of the traveling (i.e., going to headquarters) or the employee is working at home which may create family/work tensions.

The frequency of identifying issues dealing with communications, teamwork, differences across sites, career development/recognition, different management challenges caused by the remote environment, and training issues were fairly similar for both managers and employees.

\section{Phase 1 Findings - Best Practice Suggestions}

After identifying the key issues in each focus group, discussion centered on practices that were or could be used to address the issues. A lengthy list of the best practices and ideas were generated from the focus groups. The major items are summarized below.

It was suggested that a high degree of trust between manager and employee facilitates remote work. Trust can be enhanced through communications and developing a relationship. Therefore, the stronger the personal relationship, the higher the trust and the more communications, the higher the trust.

Frequent communications are necessary to maintain a feeling of being informed and part of the organization for an isolated worker. Therefore, the more frequent the communications, the higher the employee commitment and involvement. Due to the remote environment, communications often have to be electronic. Therefore, the more information technology (IT) available, the higher the employee effectiveness.

New remote workers need contact with experienced personnel in order to understand and adopt the organization's policies, expectations, and culture. Therefore, the more time spent in training with others, or in a buddy/mentor relationship, the stronger the match between the remote worker's perception of corporate climate/culture and practices and the non-remote worker's perceptions. Designating champions and resources can help the new person identify more quickly experienced people who can help in certain areas.

The remote work environment adds to the standard work burden, due largely to travel since some face to face communication is needed. This creates work/family conflict and work stress, due to working longer hours. Focus group participants suggested that travel should be seen as a last resort. Use all other forms of communication technology first and make sure that the travel is absolutely necessary. Establishing expectations regarding the amount of face-to-face time that will be available and for what, is very valuable.

The amount of face to face communication required decreases as the manager and remote worker build experience and build a relationship. Therefore, since the reduced need for face to face communications reduces travel demands, work/family conflict and work stress decreases as experience increases and trust builds.

Other ideas and best practices suggested in the focus groups included:

- It is hard to monitor and/or measure productivity in a remote work environment. Expectations should shift toward a discipline/results oriented focus.

- Responsibility should be delegated effectively (i.e., set parameters, objectives, expectations and priorities and give the resources needed).

- Trust is needed in coaching so that workers feel safe in asking for help. The manager must also be accessible and available.

- Face to face contact is needed for developing relationships and dealing with negative situations.

- Managers should value and support social activities and team building activities which help build relationships.

- Administrative support helps, especially for work at home (WAH) or isolated remote workers (i.e., working on their own).

- The remote worker needs to be organized and needs certain skills to be effective. These include: time management skills, ability to set objectives, adequate typing skills, office 
management skills, and the skills to use whatever IT tools they have available. Initiative and self-motivation are also critical traits for effective remote workers.

- Standardization of policies/practices across sites will reduce the chance for confusion and perceptions of unequal treatment.

- Career development and recognition: an employee's visibility is less when they are out of the head office so they have to work at being seen. Managers should recognize that recognition can be a problem and give recognition where it is deserved.

- Managers should support training and make it part of the performance evaluation process so that the employee also takes responsibility for it.

\section{DEVELOPMENT OF HYPOTHESES FROM THE FINDINGS OF PHASE 1 AND SUGGESTIONS IN THE LITERATURE}

The role of information technology was identified as a strong enabler by most of the focus groups and by various authors in the literature. The level of connectivity provided to remote people was shown to be very important. People that were not well connected wanted more capabilities including voice-mail, electronic-mail, groupware, and the perceived ultimate capability, videoconferencing. Participants that were well connected realized the value of it. As one participant put it, IT was "their lifeline" to the rest of their work group and the organization. Therefore, examining the level of connectivity and its impact on the employee's perception of remote work and productivity is warranted.

H1: Higher levels of connectivity will positively impact the remote worker's attitude toward working remotely.

The focus group findings also suggested that more frequent communications reduced feelings of isolation in a remote worker which increases organizational commitment. Since communications often have to be electronic in a remote setting, this suggests that high levels of connectivity, which enables electronic communications, may lead to higher levels of employee commitment.

H2: Frequent communications will increase the remote employee's organizational commitment.

H3: Higher connectivity will increase the remote employee's organizational commitment. Both the literature and phase 1 research suggested that trust between the manager and employee is an important ingredient since face-to-face supervision is limited. Trust is developed through effective communications, both formal and informal, as well as through mutual performance. Therefore:

H4: Higher levels of trust between the manager and employee will lead to a more effective remote work environment.

Consistent with the literature, maintaining or developing an appropriate corporate culture in a dispersed work environment was found to be a key issue with many of the participants. This was especially true in companies that viewed their corporate culture as a valuable asset. Replacing the informal sharing of values and stories that occurs naturally when people are physically together has to be replaced in a virtual setting by explicit efforts that will typically fall upon the manager's shoulders. Therefore, it may be that remote employees develop different perceptions of the organization's culture.

H5: Remote employees will have a different perception than non-remote employees of the organization's corporate culture.

The extra burdens imposed by remotely working suggests that remote workers will have higher job stress than non-remote workers. The focus group research also suggested that this job stress declines as experience increases and trust between the manager and employee increases. Therefore:

H6: Remote employees will have higher job stress than non-remote employees.

H7: The job stress of remote employees will be less for more experienced employees.

H8: $\quad$ Higher levels of trust between the manager and employee will lead to lower levels of job stress for remote employees.

\section{PHASE 2 - TESTING THE HYPOTHESES}

\section{Research Methodology}

Data were gathered from both remotely-managed employees and non-remotely-managed employees in a large Canadian insurance company via a questionnaire. Both remotely-managed and locally-managed employees received the same questionnaire. All recipients of the questionnaire received a reminder letter two weeks after the initial mailing of the questionnaire. After six weeks, 123 out of 184 questionnaires had been returned for a response rate of $66.8 \%$.

Trust, organizational climate, job satisfaction, organizational commitment, and job stress were measured in the questionnaire with existing scales taken from the literature that had demonstrated 
acceptable psychometric properties in previous studies. Trust was measured using an 11 item scale developed by McAllister (1995) which captures two dimensions of trust: affect-based trust and cognition-based trust. Fineman's (1975) Job Climate Questionnaire (25 items long) was used to measure organizational climate. A measure of organization climate was chosen over a culture measure since organizational climate was seen to fit better with this study. Organizational climate has a somewhat shorter time frame (relatively enduring) than organizational culture (highly enduring) and climate is more practice oriented, operating at the level of attitudes and values (Moran \& Volkwein, 1992). Warr, Cook and Wall's (1979) 15 item scale was used to assess job satisfaction. The nine-item short form of Mowday, Steers and Porter's (1979) Organizational Commitment Questionnaire scale was used to measure organizational commitment.

New scales were developed to measure the rest of the required measures. Degree of connectivity was measured by asking the respondents which of the following information technologies they had: voicemail, e-mail, groupware collaborative system(s), videoconferencing. Six items were used to collect information on remotely-managed employees perceptions of the effectiveness of working remotely. Information on the frequency of communication was gathered by asking respondents to indicate how frequently, on a five point scale ranging from "never or almost never" to "daily", they used six different media (face-to-face meetings, written correspondence, telephone, e-mail, groupware, and videoconferencing) for seven different activities (i.e., asking for and receiving coaching feedback, performance feedback, other information, and staying in touch with the manager).

Scale items were checked by carrying out structured interviews with remote employees. A pre-test of the questionnaire was also carried out with experts in questionnaire design and with remote employees.

Analysis of variance (ANOVA and MANOVA) techniques were used to test the hypotheses. ANOVA was used where there was only one dependent variable. In the other cases, MANOVA, which is a technique for analyzing differences between group means in situations where there is more than one dependent variable, was used. MANOVA results are assessed in two steps. First, the overall test of significance is examined which takes into account the intercorrelations of the dependent variables. If the overall test is significant, the dependent variables can then be examined individually. If an individual item's F-test is statistically significant, then there are differences between the groups for that dependent variable.

\section{Results of Phase 2}

A summary of the characteristics of the respondents follows. About two-thirds of all of the respondents were males. The average age was 39 years and over four-fifths of the respondents were living with a spouse or significant other. Two thirds of the respondents lived with dependents. About one-third of the respondents had an undergraduate degree or graduate degree, while about one quarter had only finished secondary school. About 45 per cent of the respondents had been with the company 11 or more years. Three-quarters of the respondents had been in their present position three or more years. The respondents had worked for their present manager an average of 2.5 years. Seventy-five per cent of the respondents were non-managers (i.e., had no people reporting to them). Only twenty percent of the respondents worked at home with the vast majority of these indicated that it was easy for them to so. Eighty-seven percent of the respondents felt that remote management was a growing practice in their organization. Seventy-three percent of the respondents had voicemail, e-mail, and groupware capabilities. Twenty-two percent only had voicemail and e-mail, while four percent had only voicemail. Slightly over half of the respondents were remotely managed $(n=64)$ with the average distance between the respondent's office and their manager's being 309 kilometers. For the most part, the demographic characteristics of the remotely-managed respondents were similar to those of the locally-managed respondents. As would be expected, more remotely-managed respondents worked from their home which meant that on average, the remotely-managed respondents had a shorter commute time. The remotely-managed respondents had, on average, longer tenure in the organization while the locallymanaged respondents had worked for their present manager longer. The positions held by remotelymanaged employees appeared to be similar to those held by locally-managed employees.

As shown in Table 3, only three of the hypotheses had significant results. Hypothesis 2 was supported. Respondents in the top half of the responses regarding frequency of communications with their manager had significantly higher levels of overall organizational commitment. Hypothesis 4 was also partially supported. While trust had no significant impact on remote employees' perceptions of the effectiveness of working remotely, trust did significantly affect the remote employees' levels of job satisfaction. Individuals with high levels of trust had significantly higher job satisfaction. The individual items in the job satisfaction scale that were significantly different are listed in Table 4 . In all cases, higher satisfaction lead to higher organizational commitment. All four items are satisfaction with issues that deal with management. 
Hypothesis 8 was also supported. Employees that had higher trust between themselves and their managers had significantly lower job stress. The other hypotheses were not supported. Neither high trust nor the level of connectivity significantly impacted remote workers attitudes toward remote work or their job satisfaction. Connectivity also did not impact organizational commitment. Remote workers did not have significantly different levels of stress nor different perceptions of organizational climate than did the non-remotely managed employecs. Greater experience, either with the organization, with the current position, or with working remotely, did not significantly reduce the job stress perceived by remotely-managed employees.

Table 4: A Summary of the Results of the Analysis of Variance

\begin{tabular}{|l|l|c|c|}
\hline & Hypothesis Description & F-Statistic & Significance Level \\
\hline $\mathrm{H} 1 \mathrm{a}$ & $\begin{array}{l}\text { Impact of connectivity on remote worker's } \\
\text { attitudes toward remote work }\end{array}$ & Wilks Lambda $\mathrm{F}=0.65$ & $\mathrm{p}=.793$ \\
\hline $\mathrm{H} 1 \mathrm{~b}$ & $\begin{array}{l}\text { Impact of connectivity on remote worker's job } \\
\text { satisfaction }\end{array}$ & $\underline{\mathrm{F}}(2,60)=2.47$ & $\mathrm{p}=.093$ \\
\hline $\mathrm{H} 2$ & $\begin{array}{l}\text { Impact of frequency of communications on } \\
\text { organizational commitment (remote workers only) }\end{array}$ & $\underline{\mathrm{F}}(1,61)=6.56$ & $\mathrm{p}=.013$ \\
\hline $\mathrm{H} 3$ & $\begin{array}{l}\text { Connectivity impacts organizational commitment } \\
\text { (whole sample) }\end{array}$ & $\underline{\mathrm{F}}(2,119)=1.32$ & $\mathrm{p}=.271$ \\
\hline $\mathrm{H} 4 \mathrm{a}$ & Impact of trust on perceptions of remote work & Wilks Lambda $\underline{\mathrm{F}}=1.49$ & $\mathrm{p}=.198$ \\
\hline $\mathrm{H} 4 \mathrm{~b}$ & $\begin{array}{l}\text { Impact of trust on perceptions of remote workers' } \\
\text { job satisfaction }\end{array}$ & Wilks Lambda $\mathrm{F}=2.90$ & $\mathrm{p}=.003$ \\
\hline $\mathrm{H} 5$ & $\begin{array}{l}\text { Remote workers have a different perception of } \\
\text { organizational climate }\end{array}$ & $\underline{\mathrm{F}}(1,119)=0.31$ & $\mathrm{p}=.578$ \\
\hline $\mathrm{H} 6$ & Remote workers have higher job stress & $\underline{\mathrm{F}}(1,121)=1.52$ & $\mathrm{p}=.220$ \\
\hline $\mathrm{H} 7 \mathrm{a}$ & Greater remote work experience reduces job stress & $\underline{\mathrm{F}}(1,60)=0.33$ & $\mathrm{p}=.570$ \\
\hline $\mathrm{H} 7 \mathrm{~b}$ & Greater tenure in organization reduces job stress & $\underline{\mathrm{F}}(4,58)=1.75$ & $\mathrm{p}=.151$ \\
\hline $\mathrm{H} 7 \mathrm{c}$ & Greater experience reduces job stress & $\underline{\mathrm{F}}(3,59)=1.18$ & $\mathrm{p}=.325$ \\
\hline $\mathrm{H} 8$ & Trust reduces job stress & $\underline{\mathrm{F}}(1,62)=0.33$ & $\mathrm{p}=.048$ \\
\hline
\end{tabular}

Table 5: The Significant Dependent Variables from the MANOVA Analysis

\begin{tabular}{|c|l|}
\hline Individual Test Results & Item Description \\
\hline$(\underline{F}(1,57)=35.29, \underline{\mathrm{p}}<.001)$ & Satisfaction with your immediate boss \\
\hline$(\underline{\mathrm{F}}(1,57)=18.45, \mathrm{p}<.001)$ & $\begin{array}{l}\text { Satisfaction with relations between management and workers in the } \\
\text { organization }\end{array}$ \\
\hline$(\underline{\mathrm{F}}(1,57)=23.13, \underline{\mathrm{p}}<.001)$ & Satisfaction with the way you are managed \\
\hline$(\underline{\mathrm{F}}(1,57)=17.13, \underline{\mathrm{p}}<.001)$ & Satisfaction with the attention paid to the suggestions you make \\
\hline
\end{tabular}

* $\mathrm{p}$ value after Bonferroni adjustment

\section{DISCUSSION}

The importance of developing trust between the remote employee and his/her manager was supported by the findings. Not only did higher trust in the relationship lead to higher job satisfaction, it also lead to lower job stress. This implies that managers and employees should work hard at developing a relationship based on trust; some of the suggestions from the first phase of this study may help to achieve this.

After the strong suggestions from Phase 1 regarding the criticality of IT in a remote work setting, it was disappointing that none of the hypotheses associated with the level of connectivity were supported in Phase 2; however, there was noi a great deal of variance in the level of connectivity among the respondents which meant that the sample sizes for the groups with low connectivity was small. Repeating the study with a larger sample that has greater variance in the IT used would be necessary before drawing any conclusions regarding the impact of IT on remote worker's perceptions of remote work effectiveness and organizational commitment. Also, the support for the hypothesis that frequency of communications leads to organizational commitment does indirectly support the suggestions that IT is important in a remote setting since communications are enabled by IT in this environment.

The small sample size of the second phase of this study limited the power of the statistics and suggests that the findings be interpreted as preliminary until the study can be replicated with a larger sample. Another limitation of this study was that the participants involved in the first phase of the study were 
not a randomly selected group. Instead, they represent early innovators and individuals who were interested enough in the topic to commit their time to it. Therefore, the ability to generalize the findings may be limited. Again, further studies will help to determine the generalizability of the findings.

In addition to future questionnaire-based studies with larger sample sizes, more qualitative research, such as longitudinal case studies, would be valuable. While questionnaires lend themselves to quantitative analysis, case studies would gather richer, deeper information. This information would be valuable in examining issues such as the role of informal communications in a remote management setting.

The results from this research study makes a contribution, from a practitioner point of view, by identifying key issues regarding remote management and offering suggestions to deal with the issues. The findings will also help guide future research by identifying important aspects of remote management to focus on and suggesting several hypotheses for future research. For example, issues such as the use of information technology, communications, and the role of trust, are all important remote management and remote work issues that warrant further study.

\section{REFERENCES}

Beyers, M. (1995) Is There a Future for Management? Nursing Management, Vol 26, Issue 1, pp 24 25.

Bleecker, S. E. (1994) The Virtual Organization. Futurist, Vol 28, Issue 2, pp 9-14.

DeSanctis, G. (1984) Attitudes Toward Telecommuting: Implications for Work-at-Home

Programs. Information \& Management, Vol 7, Issue 3, pp 133-139.

Duxbury, L. E., Higgins, C. A. \& Irving, R. H. (1987) Attitudes of Managers and Employees to

Telecommuting, INFOR, Vol 25, Issue 3, pp 273-285.

Fineman, S. (1975) The Influence of Perceived Job Climate on the Relationship Between

Managerial Achievement Motivation and Performance, Journal of Occupational

Psychology, Vol 48, pp 113-124.

Freedman, D. H. (1993) Quick Change Artists, CIO, Vol 6, Issue 18, pp 32-28.

Gerber, B. (1995) Virtual Teams, Training, April, pp 36-40.

Greengard, S. (1994) Making the Virtual Office a Reality, Personnel Journal, September, pp 66-79.

Hamilton, C. (1987) Telecommuting, Personnel Journal, Vol 66, Issue 4, pp 90-101.

Handy, C. (1995) Trust and the Virtual Organization, Harvard Business Review, June, pp 40-50.

Illingworth, M. M. (1994) Virtual Managers, InformationWeek, June 13, pp 42-58.

Jenner, L. (1994) Are You Ready for the Virtual Workplace? HR Focus, Vol 71, Issue 7, pp 15-16.

Judd, C. M., Smith, E. R., \& Kidder, L. H. (1991) Research Methods in Social Relations, Toronto: Holt, Rinehart and Winston, Inc.

Judkins, P., West, D. \& Drew, J. (1985) Networking in Organizations: The Rank Xerox Experiment, Gower.

Krueger, R. A. (1989) Focus Groups: A Practical Guide for Applied Research, Newbury Park, California: Sage Publications.

Lucas, H. C., Jr. \& Baroudi, J. (1994) The Role of Information Technology in Organization Design, Journal of Management Information Systems, Vol 10, Issue 4, pp 9-23.

McAllister, D. J. (1995) Affect- and Cognition-Based Trust as Foundations for Interpersonal Cooperation in Organizations, Academy of Management Journal, Vol 38, pp 24-59.

Metzger, R. O. \& Von Glinow, M. A. (1988) Off-Site Workers: At Home and Abroad, California Management Review, Vol 30, Issue 3, pp 101-111.

Moran, E. T. \& Volkwein, J. F. (1992) The Cultural Approach to the Formation of Organizational Climate, Human Relations, Vol 45, pp 19-47.

Morgan, G. (1988), Chapter 7: Developing Skills in Remote Management. Riding the Waves of Change: Developing Managerial Competencies for a Turbulent World. San Francisco: Jossey-Bass Publishers.

Mowday, R. T., Steers, R. M. \& Porter L. W. (1979) The Measurement of Organizational Commitment, Journal of Vocational Behavior, Vol 14, pp 224-247.

Mowshowitz, A. (1994) Virtual Organizations: A Vision of Management in the Information Age, The Information Society, Vol 10, Issue 4, pp 267-288.

Nilles, J. M. (1985) Teleworking from Home, The Information Technology Revolution, Forester, T. \& Blackwell, B. (eds.).

O'Hara-Devereaux, M, \& Johansen, R. (1994) Gobalwork: Bridging Distance, Culture, and Time, San Francisco: Jossey-Bass Publishers.

Olson, M. H. (1988) Organizational Barriers to Telework, In W. Korte, \& W.J. Robinson, (Eds.), Telework: Present Situation and Future Development of a New Form of Work, North-Holland. 
Phelps, N. (1985) Mountain Bell: Program for Managers, Office Workstations in the Home, Washington, DC: National Research Council, National Academy Press.

Roderick, J. C. \& Jelley, H. M. (1991) Managerial Perceptions of Telecommuting in Two Large Metropolitan Cities, Southwest Journal of Business \& Economics, Vol 8, Issue 1, pp 35-41.

Savage, J. A. (1988) California Smog Fuels Telecommuting Plans, Computerworld, Vol 22, Issue 18, pp 65-66.

Snell, N. W. (1994) Virtual HR: Meeting New World Realities, Compensation \& Benefits Review, Vol 26, Issue 6, pp 35-43.

Walsham, G. (1994) Virtual Organization: An Alternative View, The Information Society, Vol 10, Issue 4, pp 289-292.

Warr, P., Cook, J. \& Wall, T. (1979) Scales for the Measurement of Some Work Attitudes and Aspects of Psychological Well-being, Journal of Occupational Behavior, Vol 52, pp 129-148. 